\title{
Posições do ANDES/Sindicato Nacional para o Trabalho dos Professores Brasileiros
}

DOI: https://doi.org/10.35168/2176-896X.UTP.Tuiuti.2021.Vol7.N63.pp4-22 


\section{Posições do ANDES/Sindicato Nacional para o Trabalho dos Professores Brasileiros}

\section{Resumo}

Apresentam-se resultados de um projeto de pesquisa em nível de Iniciação Científica que teve como objeto de investigação as teses sobre o trabalho de professores da Educação Superior contidas em artigos publicados na Revista Universidade e Sociedade, veículo semestral do Sindicato Nacional dos Docentes do Ensino Superior (ANDES/SN) no período de 2015 a 2020. Trata-se de um subprojeto de um outro mais abrangente intitulado POSIÇÕES DO ANDES/SINDICATO NACIONAL PARA O TRABALHO DOS PROFESSORES BRASILEIROS (1996-2020). Configura-se como uma pesquisa bibliográfica, que procurou responder à seguinte problemática: quais as teses veiculadas nos artigos publicados na revista do ANDES/SN quanto ao trabalho dos professores da Educação Superior no período de 2015 a 2020? O objetivo geral foi assim definido: explicitar as posições de pesquisadores quanto ao trabalho de professores da Educação Superior em tempos de tantas mudanças educacionais. O estudo possibilita apontar que é um tema que aparece com certa frequência na revista do ANDES e sinaliza para os desafios que estão postos à classe dos professores da Educação Superior no Brasil.

Palavras-chave: ANDES-SN. Trabalho do professor. Educação Superior. 


\section{Positions of the ANDES/National Union for the Work of Brazilian Teachers}

\section{Abstract}

The results of a research project at the Scientific Initiation level are presented, which had as its object of investigation the theses on the work of Higher Education teachers contained in articles published in the Magazine Universidade e Sociedade, a biannual vehicle of the National Union of Higher Education Teachers (ANDES/SN) in the period from 2015 to 2020. It is a subproject of a more comprehensive one entitled POSIÇÕES DO ANDES/SINDICATO NACIONAL PARA O TRABALHO DOS PROFESSORES BRASILEIROS (1996-2020). It is configured as a bibliographic research, which sought to answer the following issue: what are the theses published in the articles published in the ANDES/ SN magazine regarding the work of Higher Education teachers in the period from 2015 to 2020? The general objective was defined as follows: to clarify the positions of researchers regarding the work of Higher Education teachers in times of so many educational changes. The study makes it possible to point out that it is a topic that appears with some frequency in the ANDES magazine and points to the challenges that are posed to the class of Higher Education teachers in Brazil.

Keywords: ANDES-SN. Teacher's work. College education. 


\section{Posições do ANDES/Sindicato Nacional para o Trabalho dos Professores Brasileiros}

\section{Introdução}

Assim, ensino e aprendizagem só serão motivados se seu processo se der como processo de pesquisa. Daí estarem cada vez mais reconhecidas e implementadas as modalidades de atividades de iniciação ao procedimento científico, envolvendo estudantes em práticas de construção de conhecimento, mediante participação em projetos de investigação (SEVERINO, 2007, p. 26).

Este artigo tem como tema o trabalho de professores da Educação Superior e justificase em virtude dos impactos das recentes políticas para este nível de ensino e com prática de iniciação científica. A educação à distância em expansão nas últimas décadas, o trabalho híbrido que se estabeleceu com a pandemia da COVID-19, a privatização deste setor educacional, as políticas para a Universidades públicas tem provocado mudanças no trabalho dos professores, fala-se em trabalho intensificado, industrializado, precarizado, em carreias múltiplas.

O que se apresenta é resultado de pesquisa bibliográfica que procurou captar na Revista Universidade e Sociedade (US) do Sindicato Nacional dos Docentes das Instituições de Ensino Superior (ANDES/SN), o que os pesquisadores que ali têm publicado seus artigos refletem sobre o tema.

A pesquisa bibliográfica, segundo Antônio Joaquim Severino,

é aquela que se realiza a partir do registro disponível, decorrente de pesquisas anteriores, em documentos impressos, como livros, artigos, teses etc. Utiliza-se de dados ou categorias teóricas já trabalhados por outros pesquisadores e devidamente registrados. Os textos tornam-se fontes dos temas a serem pesquisados. O pesquisador 


\section{Posições do ANDES/Sindicato Nacional para o Trabalho dos Professores Brasileiros}

trabalha a partir das contribuições dos autores dos estudos analíticos constantes dos textos (SEVERINO, 2007, p. 122).

Entendemos que é este o tipo de pesquisa que se realiza quando investigamos nas produções publicadas na revista do ANDES/SN o trabalho dos professores da Educação Superior (ES) no período de 2015 a 2020. Trata-se de um subprojeto de um outro mais abrangente intitulado POSIÇÕES DO ANDES/SINDICATO NACIONAL PARA O TRABALHO DOS PROFESSORES BRASILEIROS (1996-2020). Na Investigação realizada procurou-se responder à seguinte problemática: quais as teses veiculadas nos artigos da revista Universidade e Sociedade quanto ao trabalho dos professores da Educação Superior no período de 2015 a 2020 ?

Esta investigação agrega tanto a pesquisa quantitativa o que permitiu apontar o total das edições da revista consultada, as que estão na rede mundial de computadores (internet) e ainda aquelas onde encontramos artigos aderentes ao nosso tema de investigação. Já a pesquisa qualitativa também se fez presente, uma vez que apresentamos excertos dos artigos, a fim de se explicitar as teses dos autores a respeito do tema, nomeadamente quanto o que aparece de maneira acentuada- a precarização do trabalho docente.

Este texto inicia com apontamentos sobre o ANDES/SN e a sua revista Universidade e Sociedade, para em seguida apresentarmos a pesquisa realizada nas edições desse veículo, publicadas entre 2015 e 2020, que serviram de fonte ao estudo que se realiza. Dedicamos as considerações finais a resultados do estudo. 


\section{Posições do ANDES/Sindicato Nacional para o Trabalho dos Professores Brasileiros}

\section{Apontamentos históricos sobre o ANDES e sua revista:Unversidade e Sociedade}

Primeiramente, para se compreender sob qual conjuntura o ANDES/SN foi criado - tanto histórica quanto politicamente - é necessário analisar o contexto anterior a sua criação, pois, como veremos, a fundação desse sindicato é o resultado de diversos acontecimentos históricos da luta dos docentes do país.

De acordo com MIRANDA (2011), o período compreendido entre a década de 60 e 80 foi um período no Brasil de criação de diversas Associações de Docentes (ADs). Desta forma, em 1960 ocorre, em Recife, no Estado de Pernambuco (PE), a Confederação dos Professores Primários do Brasil, que expressa experiências de caráter nacional com relação a educação. E, ainda de acordo com a autora, a formação de organizações de caráter nacional apenas vieram a surgir tão tardiamente na história do país por três razões: a dimensão territorial do Brasil somado a falta de um plano nacional para a educação; a dicotomia entre a educação básica e a superior e a heterogeneidade nas formas de organizações.

A partir da década de 1970, a classe dos professores e as ADs passaram a estabelecer maior presença em congressos nacionais, assumindo cada vez mais seu caráter político, participando do debate sobre a formação do professor. Assim, em 1979 ocorre o $1^{\circ}$ Encontro Nacional de ADs, em São Paulo (SP), capital, com a presença de 24 associações, onde assentaram que a democratização da universidade é parte integrante da luta pela democratização da sociedade (MIRANDA, 2011, p.44).

Em 1981 foi fundada a Associação Nacional dos Docentes do Ensino Superior (ANDES), uma vez que era vetado, de acordo com a Constituição vigente ${ }^{1}$, aos professores da rede pública

1 Refere-se a Constituição Brasileira de 1967 promulgada durante o Regime Militar. 


\section{Posições do ANDES/Sindicato Nacional para o Trabalho dos Professores Brasileiros}

a filiação sindical. No ano seguinte, a então Associação teve aprovado seu Caderno 2, que tem como objetivo, segundo o próprio texto, o de publicamente expressar "a posição crítica dos docentes sobre a educação superior e as propostas atualizadas para a universidade brasileira e para a educação técnica e tecnológica nas Instituições de Ensino Superior (IES)" (ANDES, 2013). Tal texto, foi aprovado pelo V CONAD (Conselho Nacional de Associações Docentes), que foi então apresentado ao Ministério da Educação (MEC). Ainda nesse mesmo ano o ANDES estruturou em uma articulação com a Ordem dos Advogados do Brasil (OAB), com o Sociedade Brasileira para o Progresso da Ciência (SBPC) e a Associação Brasileira de Imprensa (ABI), uma proposta de reestruturação da universidade brasileira, assim expressa:

1. manutenção e ampliação do ensino público e gratuito; 2. autonomia e funcionamento democrático da universidade, com base em colegiados e cargos de direção eletivos; 3 . estabelecimento de um padrão de qualidade para o ensino superior que estimule a pesquisa e a criação intelectual nas universidades; 4. dotação de recursos públicos orçamentários suficientes para o ensino e a pesquisa nas universidades públicas; 5 . criação de condições para adequação da universidade à realidade brasileira; 6. garantia do direito à liberdade de pensamento nas contratações e nomeações para a universidade, bem como no exercício das funções e atividades acadêmicas, princípios sobre os quais se estruturou a "Proposta das Associações de Docentes e da ANDES para a Universidade Brasileira (ANDES, 2013, p.11).

Em alinhamento a esse debate, em 1985, no mês de maio, a ANDES, em conjunto com a União Nacional dos Estudantes (UNE) e da Federação dos Servidores das Universidades Brasileiras (FASUBRA), promove o Seminário Nacional sobre a Reestruturação da Universidade, em Brasília (DF). Em junho do mesmo ano, o XI CONAD, após a organização documental e de discussões 


\section{Posições do ANDES/Sindicato Nacional para o Trabalho dos Professores Brasileiros}

anteriores - como, por exemplo, o debate promovido em 1983 pela ANDES, intitulado "O Público e o Privado, o Poder e o Saber: a Universidade em Debate" -, obtiveram propostas conclusivas a respeito desta reestruturação proposta, ratificando este documento em junho de 1986.

Com a Constituição cidadã em 1988, que marca igualmente a queda do regime militar no país, assegura-se, então, o direito de o servidor público de sindicalizar-se. Assim sendo, o ANDES torna-se um Sindicato, alterando também sua nomenclatura, agora ANDES/SN, podendo, como sindicato, representar muito mais os docentes em questões políticas. A década de 1990 é marcada como década de grandes propostas e avanços para a redemocratização das universidades, aprovando-se inclusive um novo projeto de Lei de Diretrizes e Bases da Educação Nacional que tramitou no Congresso Nacional desde 1988. Após muitos debates e disputas, alterações e substituições do projeto inicial, a referida Lei foi promulgada em dezembro de 1996. Foi o resultado possível, pois, o MEC interferiu no projeto que vinha sendo longamente construído pelos docentes e seus representantes, descaracterizando-o, já sob os cânones neoliberais que em muito atropelaram a autonomia das universidades, garantida pela Constituição cidadã.

Ao longo da atuação da ANDES e depois do ANDES/SN, os docentes organizados em congressos foram refletindo e debatendo sobre os princípios e concepções de Universidade, trabalho que resultou em escritos, posições e reivindicações. Materiais foram sendo elaborados e em 1996 foi editado o Caderno ANDES n 2, com as orientações e princípios para a universidade brasileira. Várias vezes reeditado, esse caderno tem sua última edição no ano de 2013, "O Cadernos ANDES n ${ }^{\circ} 2$ passaria a conter as concepções fundamentais do ANDES/SN sobre as instituições de ensino superior" (ANDES, 2013, p. 14).

Nesta breve apresentação, temos que o ANDES/SN, inicialmente uma associação, originada em um período de novas formulações políticas e reinvindicações dos professores da ES, estabeleceu-se 


\section{Posições do ANDES/Sindicato Nacional para o Trabalho dos Professores Brasileiros}

visando a real participação nas mudanças das políticas educacionais brasileiras. Neste sentido fazemse publicações, debates e congressos para lutar em prol dos docentes do país, seja em garantias salariais quanto referentes à democratização da universidade brasileira, firmando-se assim, como um dos mais relevantes sindicatos de docentes neste período histórico, mantendo-se atuante até os dias atuais.

\section{Universidade e sociedade: 0 trabalho de professores relatado e problematizado em seus artigos}

De acordo com os dados coletados no site do ANDES/SN, a publicação da revista Universidade e Sociedade (US) teve início em 1991, em comemoração aos 10 anos de existência da ANDES. Até hoje, agosto de 2021, foram publicadas 70 edições (em média, duas por ano) - 67 regulares e 3 extraordinárias. A revista está completando 30 anos, portanto.

Outra informação que vale acrescentar, é que, por volta da revista $n^{\circ} 40$ até a revista $n^{\circ} 01$, majoritariamente os artigos publicados deixam de apresentar um resumo (abstract) em seu texto, usando-se apenas a introdução para expressar a ideia inicial do artigo. Além disto, as revistas de $\mathrm{n}^{\text {os }}$ 51, 50, 49, 48, 47, 46, 45, 42, 5, 4, 3 e 2, disponibilizadas pelo ANDES/SN, não possuem um título da edição evidenciados, tal como nota-se em muitas destas edições a falta das páginas relacionadas aos dados da revista, como o ISBN, por exemplo.

E, relacionando-se a falta de material, é importante ressaltar que as revistas da edição no 06 até n 24 não constam na página eletrônica (site) do sindicato, junto as outras edições, totalizando o número de 49 revistas disponíveis para consulta através do site do próprio sindicato. 


\section{Posições do ANDES/Sindicato Nacional para o Trabalho dos Professores Brasileiros}

Tendo-se assim explicado a visão geral quantitativa que as revistas apresentam, passemos para a análise de seu conteúdo, propriamente dito. Logo, cabe dizer que foram analisadas as 49 revistas disponibilizadas, considerados os seus títulos, resumos e introduções para definir qual é o tema destes tantos artigos, buscando, de forma objetiva, os artigos que versam a respeito do trabalho do professor das IES, para estabelecermos a presença do tema dentro da Revista Universidade e Sociedade, na qual constatou-se a presença de 34 artigos publicados pelo ANDES/SN, o que nos dá uma média de 0,69 publicações sobre o tema em questão por revista publicada, demonstrando assim a presença do tema no periódico.

Destes 34 artigos que apresentam o tema do trabalho do professor da Educação Superior, 14 deles referem a precariedade do trabalho do professor da Educação Superior, partindo, em sua maioria, de perspectivas diferentes, mas que convergem em algum ponto do texto para a precariedade. Ora, esta precariedade é definida pelos artigos em questão por: 1. descaracterização da profissão, deslegitimando seu trabalho; 2. corte de verbas do Sistema público; 3. sobrecarga de trabalho; 4. expansão do número de contratações temporárias; 5. professor como professional de multifunções; 6. Carreira universitária e desvalorização salarial; 7. contrato de trabalho por serviços prestados.

Estes elementos presentes no trabalho dos professores da Educação Superior têm a ver com as recentes políticas de expansão privada de oferta de ES: a presença do Ensino a Distância (EaD); o tipo de instituições (Universidades, Faculdades, Centros universitários); a flexibilização da chegada de estudantes aos cursos superiores e o próprio Fundo de Financiamento Estudantil (FIES), a política de contenção para as IES públicas.

Os artigos publicados na Revista Universidade e Sociedade, veículo do ANDES/SN, mantém afinidade com o projeto de Universidade Pública.

Então, a compreensão da precarização em tela decorre do projeto de Universidade que se vai tendo hegemonia. Considere-se inicialmente, que ANDES/SN, como visto no início deste artigo, 


\section{Posições do ANDES/Sindicato Nacional para o Trabalho dos Professores Brasileiros}

apresentou, em conjunto da OAB e da SBPC uma proposta de reestruturação da universidade brasileira, que defendia a manutenção do ensino público, a autonomia das universidades, estímulo à pesquisa, políticas orçamentárias que sustentem a pesquisa, o ensino e a extensão, adequação da universidade à realidade brasileira, e garantia de liberdade de pensamento (ANDES, 2013, p.11). Porém, como os artigos do periódico denunciam, as medidas adotadas pelo governo vão na contramão desse projeto. Em desdobramentos da política educacional, segundo apontam os articulistas da referida revista, houve o desmantelamento da educação, o engessamento do ser professor, a entrada do capital privado nas instituições e a sobrecarga do professor.

Tratando-se do que se entende sobre a precarização, aponta-se a perda da autonomia do trabalho do professor, que está cada vez mais "engessado" em seu trabalho, esteja ele lecionando em sala, esteja ele pesquisando em programas de pós-graduação - pois cada vez mais se estreitam as formas, os objetivos e as políticas de financiamento para a pesquisa -, já que os professores vem abandonando a pesquisa, tal como os pesquisadores, pois como retrata Bianchetti (2011, p. 145), "a CAPES está induzindo a maneira como se organiza, como funciona, enfim, como fazemos a pós-graduação, hoje, estamos afirmando que a autonomia está limitada, reduzida, e que muito do que fazemos, o fazemos desta forma, ou encerrados nesta fôrma, porque não temos liberdade de fazer de outra."

E, a partir do momento em que o professor perde sua autonomia, fica ele à mercê das instituições de ensino que, para atender a demanda quantitativa de alunos e cumprir o cronograma das Instituições de Ensino Superior (IES), engessa ao máximo as possibilidades de o docente organizar o trabalho pedagógico, recorrendo, em suma, ao ensino tradicional e estático, resumindo o professor a mero aplicador de material e assim desconsiderando seu potencial intelectual (FLORES, 2018, p. 65). 


\title{
Posições do ANDES/Sindicato Nacional para o Trabalho dos Professores Brasileiros
}

Além dessas considerações, Paiva e Bauer apontam que face a este engessamento e falta de autonomia, o docente encontra-se também cada vez mais pressionado a aceitar a expansão do ensino superior público sem que haja a necessária estrutura para tal,

\begin{abstract}
frente à necessidade de expansão da cobertura, do número de cursos e programas e com um orçamento incongruente, a opção tem sido, entre outras, ampliar o trabalho precário dos professores universitários, ou seja, a expansão do ensino superior é sustentada, em parte, pela ampliação da exploração dos trabalhadores da educação que atuam, principalmente, como docentes. (PAIVA; BAUER, 2016, p. 96).
\end{abstract}

Isto aponta para a ausência de condições para a realização do trabalho docente que envolve pesquisa, ensino e extensão, daí se entender que se vive uma condição de precarização

Em suma, essas políticas educacionais adotadas são parte de um movimento da desresponsabilização do Estado para com a Universidade pública, e da transformação da educação em "mercado de investimentos".

Instala-se na Universidade uma gestão gerencialista caracterizada pela redução de investimentos e controle do que se faz,

A educação brasileira, em especial as instituições de ensino superior (IES), tem sido alvo das transformações sofridas pela universidade e pelo mundo do trabalho, conforme já sinalizamos anteriormente, uma vez que funcionam de acordo com os moldes de controle de qualidade, no intuito de aumentar a produtividade e diminuir os custos com a força de trabalho, mediante novas formas de contratação e prestação de serviços requeridos pela reestruturação (LIMA; LIMA, 2017, p. 93). 


\title{
Posições do ANDES/Sindicato Nacional para o Trabalho dos Professores Brasileiros
}

Essa política compromete a natureza do trabalho dos professores ao verem delimitados os objetivos da pesquisa e da expansão do conhecimento.

Uma outra realidade que aponta para a precarização do trabalho na Educação Superior é a cada vez maior presença do trabalho temporário. "Segundo Pinto (2010), o termo "professor substituto" apareceu de forma mais expressiva nas universidades federais brasileiras a partir da década de 1990. Anteriormente, havia outros termos para denominar os docentes fora da carreira, como aulistas e horistas" (LIMA; LIMA, 2017, p. 93).

Os contratos temporários tem sérias consequências para os professores, retira-lhes a condição de estabilidade, de planejarem sua formação continuada e o desenvolvimento de projetos de pesquisa e ensino.

\begin{abstract}
A intensificação do trabalho docente, a redefinição de suas atribuições - tanto em sua forma como em seu conteúdo - e a divisão estabelecida pela crescente contratação de professores substitutos como tática para ampliação do ensino superior nas instituições públicas são estratégias para desarticulação da carreira docente - uma conquista histórica - e do projeto de universidade em que pesquisa, ensino e extensão são indissociáveis. Mudam os atores em cena, muda a cena e novos atores são formados, adaptados ao novo cenário (LIMA; LIMA, 2017, p. 93).
\end{abstract}

A Lei que regulamenta a contratação temporária é a de n. 8.745 de 1993, previu esse contrato para certos casos, conforme o Art. $1^{\circ}$. Para atender a necessidade temporária de excepcional interesse público, os órgãos da Administração Federal direta, as autarquias e as fundações públicas poderão efetuar contratação de pessoal por tempo determinado, nas condições e prazos previstos nesta Lei (BRASIL, 1993). Já em seu Art. $2^{\circ}$ está apontado que a referida Lei se aplica em casos de 


\section{Posições do ANDES/Sindicato Nacional para o Trabalho dos Professores Brasileiros}

"excepcional interesse público" como: I- assistência a situações de calamidade pública; II - combate a surtos endêmicos; III-realização de recenseamentos; IV - admissão de professor substituto e professor visitante; V - admissão de professor e pesquisador visitante estrangeiro; VI - atividades especiais nas organizações das Forças Armadas para atender a área industrial ou a encargos temporários de obras e serviços de engenharia. Quando para professores, há que ser respeitado o percentual máximo de $20 \%$ do total de docentes efetivos em exercício na instituição e aplica-se quando para suprir a falta de professores por exoneração, demissão, aposentadoria, falecimento, licença ou afastamentos obrigatórios.

Essa política leva às IES instabilidade e compromete o princípio da isonomia por acarretar diferentes situações para formações assemelhadas: de uma lado, para o professor substituto instalase a temporalidade estreita para um trabalho que exige continuidade e, permanência, de outro, para o professor efetivo uma sobrecarga de trabalho "nas atividades de pesquisa, extensão, coordenação de curso, orientações de dissertações e teses, uma vez que os professores substitutos são excluídos destas atividades, exercendo apenas atividades de sala de aula” (LIMA; LIMA, 2017, p. 93).

É observando estas condições de trabalho na Educação Superior que pesquisadores apontam para uma "intrínseca relação entre a flexibilização do trabalho docente e o papel exercido pela universidade operacional no contexto de acumulação flexível do capital" (LIMA; LIMA, 2017 p. 96).

Nesta perspectiva Silva, Freitas e Kitagawa sinalizam que "não bastassem os problemas internos das instituições de ensino, temos as notórias e inúmeras retiradas de direitos trabalhistas e previdenciários dos servidores públicos, que causam profundo mal-estar na categoria." (SILVA; FREITAS; KITAGAWA, 2018, p. 104), fazendo com que cada vez mais os professores sintam-se acuados tanto pelo Estado quanto pelas instituições privadas, já que "grande parte dos professores 


\section{Posições do ANDES/Sindicato Nacional para o Trabalho dos Professores Brasileiros}

não tem seu vínculo de trabalho reconhecido ou este é assumido como sendo precário até mesmo pelas autoridades do país." (PAIVA; BAUER, 2016, p. 96)

Neste cenário, o professor, já em processo de descaracterização profissional, passa a buscar a especialização e a produção acadêmica não mais pela ação social e pela ciência, pois "nesta lógica produtivista, o pesquisador/professor envereda pela necessidade de publicar para pontuar: a valoração de seu trabalho e conhecimento é quantitativa" (GUIMARÃES; MONTE; FARIAS, 2013, p. 39), de forma que a seus modos, sua busca pela pós-graduação é apenas um meio de "promoção" na universidade, um investimento puramente financeiro e privado.

Em síntese, podemos afirmar que, para o ANDES/SN, por meio das publicações de artigos na Revista do sindicato- Universidade e Sociedade-, o trabalho dos professores da Educação Superior é um tema importante, presente em seu projeto editorial, e em especial a precarização do professor, que se constitui pela crescente dificuldade de os professores realizarem seu trabalho de ensinar, produzir conhecimento, divulga-lo e difundi-lo.

\section{Considerações finais}

Esta pesquisa procurou captar dados sobre o trabalho de professores das IES na Revista do ANDES-SN, sobretudo nas públicas.

Explicitamos que se trata de uma investigação do tipo bibliográfica uma vez que as fontes são os registros contidos e analisados por autores em seus artigos. Informamos o leitor sobre a criação do ANDES/SN e acerca de seu veículo- Universidade e Sociedade. Como expresso anteriormente a referida revista vem sendo publicada desde 1991. Analisaram-se 49 edições e constatou-se que o 


\section{Posições do ANDES/Sindicato Nacional para o Trabalho dos Professores Brasileiros}

tema do trabalho do professor da ES se faz recorrente nos números consultados da revista. Constatouse que, nas 49 revistas analisadas e no total dos artigos nelas publicadas existe uma margem de 0,69 artigos sobre o trabalho do professor da Educação Superior por edição, totalizando 34 artigos, e que, dentro deste tema, existe uma preocupação em destaque, que é a da precarização do trabalho do professor, expressa em 14 artigos ao longo das referidas publicações.

Ademais, se buscou compreender, através de excertos destes 14 artigos, o que o ANDES/SN compreende como precarização da classe de professores (docentes e/ou pesquisadores), uma vez que a discussão se faz presente. Entende-se que há essa precarização quando as políticas educacionais do Estado se caracterizam pela desresponsabilização da educação, abrindo cada vez mais espaço para a privatização e o mercantilismo, práticas estas, que o ANDES/SN é contrário, uma vez que defende que a educação deva ser pública e assegurada pelo Estado, de forma democrática como prevê a Constituição Cidadã de 1988.

Deu-se destaque à presença do trabalho temporário na contratação de professores que compromete a natureza do ofício de ensinar e pesquisar e que aproxima a Universidade de um gerencialismo empresarial. Além disto, instala relações de trabalho onde a isonomia fica comprometida, expande-se a "exigência de produtividade, (e) convive-se com a (in)certeza do fim do contrato de trabalho” (LIMA; LIMA, 2017, p. 96).

Por fim, há que se apontar que esta pesquisa, no nível de Iniciação Científica possibilitou o exercício de uma investigação do tipo bibliográfico e o contato com textos elaborados por pesquisadores que trazem sínteses de investigações de mestrado e doutorado refletindo os debates a respeito da Educação Superior brasileira. 


\section{Posições do ANDES/Sindicato Nacional para o Trabalho dos Professores Brasileiros}

Como diz o professor Severino, que nos serve de epígrafe, “iniciar-se à vida científica é vivenciar a forma mais privilegiada de aprender [...]. Só se aprende e só se ensina pela efetiva prática da pesquisa" (SEVERINO, 2007, p.26).

Ainda, a revista Universidade e Sociedade, como já apontado, está em edição há 30 anos, publica reflexões de estudiosos sobre a Educação Superior e suas relações com a formação social brasileira. Em sua mais recente publicação, a segunda deste ano de 2021, a US assinala que a melhor maneira de celebrar os 40 anos do ANDES/SN e os 30 da sua revista é contar suas lutas, entre elas a do autogoverno, "um pleito presente desde o surgimento (1981) da Associação Nacional dos Docentes de Ensino Superior (Andes)" (LEHER, 2021, p. 21), aliás, a afirmação de um direito constitucional.

\section{Referências}

ANDES. História. Disponível em <https://www.andes.org.br/sites/historia>. Acesso em: 21 jun. 2021.

BIANCHETTI, Lucídio. Pós-graduação na ibero-américa. Conflito de temporalidades. Tradição x Modernidade. PERSPECTIVA, Florianópolis, v. 29, n. 2, p. 649-671, jul./dez. 2011.

BRASIL. Lei $\mathbf{n}^{\mathbf{0}} \mathbf{8 . 7 4 5}$, de 9 de dezembro de 1993. Dispõe sobre a contratação por tempo determinado para atender à necessidade temporária de excepcional interesse público, nos 


\section{Posições do ANDES/Sindicato Nacional para o Trabalho dos Professores Brasileiros}

termos do inciso IX do Art. 37 da Constituição Federal, e dá outra providências. Disponível em https:/www2.camara.leg.br/legin/fed/lei/1993/lei-8745-9-dezembro-1993-363171publicacaooriginal-1-pl.html. Consulta em 30/8/2021.

FLORES, Renata. Ser e não ser: docência precarizada na Educação Básica Federal. In: Revista Universidade e Sociedade, XXVIII, no 61, 2018. Disponível em < https://www.andes.org. br/sites/universidade_e_sociedade>. Acesso em: 28 jun. 2021.

GUIMARÃES, André; MONTE, Emerson; FARIAS, Laurimar. O trabalho docente na expansão da educação superior brasileira: entre o produtivismo acadêmico, a intensificação e a precarização do trabalho. In: Revista Universidade e Sociedade, XXII, no 52, 2013. Disponível em < https://www.andes.org.br/sites/universidade_e_sociedade>. Acesso em: 28. jun. 2021.

LEHER, Roberto. O ANDES/SN- e o auto governo da Universidade Pública. In: Revista Universidade e Sociedade. Ano XXXI, n. 68, julho de 2021. Disponível em: <https:// www.andes.org.br/sites/universidade_e_sociedade>. Acesso em 29 jun. 2021.

LIMA, Daniele Gomes de; LIMA, e Rita de Lourdes. A precarização do trabalho docente no contexto da universidade operacional e suas inflexões na condição do professor substituto. In: Revista Universidade e Sociedade, Ano XXVII - No 60 - julho de 2017. Disponível em: < https://www.andes.org.br/sites/universidade_e_sociedade>. Acesso em 29 jun. 2021.

MIRANDA, Kênia. As lutas dos trabalhadores da educação: do novo sindicalismo à ruptura com a CUT. 400 f. Niterói, 2011. Tese (Doutorado em Educação e História) Universidade Federal, Fluminense, Rio de Janeiro, 2011. 


\section{Posições do ANDES/Sindicato Nacional para o Trabalho dos Professores Brasileiros}

PAIVA, Luís; BAUER, Carlos. Elementos do sindicalismo universitário mexicano - Da resistência ao processo de precarização do trabalho docente (1990-2010). In: Revista Universidade e Sociedade, XXVI, no 57, 2016. Disponível em: < https://www.andes.org.br/ sites/universidade_e_sociedade>. Acesso em 29 jun. 2021.

SEVERINO, Antônio. Metodologia do trabalho científico. São Paulo: Cortez, 2007.

SILVA, Marluce; FREITAS, Paula; KATAGAWA, Adriana. Adoecimento e desvalorização das atividades docentes na Universidade Federal de Mato Grosso (UFMT). In: Revista Universidade e Sociedade, XXVIII, no 62, 2018. Disponível em <https://www.andes.org. br/sites/universidade_e_sociedade>. Acesso em: 28 jun. 2021. 